\title{
Small rodent population synchrony in western Sweden. Effects of landscape structure
}

\author{
Jon Loman
}

Loman, J. 2008. Small rodent population synchrony in western Sweden. Effects of landscape structure. - Web Ecology 8: 14-21.

\begin{abstract}
Small rodents were captured in two regions in western Sweden. One represents an agricultural landscape were captures were made in 19 small habitat islands and in two small forests. The other represents a forest region were captures were made in four sites in a continuous forest. The captures were made for seven years. There were no clear indications of cyclicity. Within both regions, wood mice captures were in synchrony among sites. For bank voles, this was only true in the forest region and for field voles in the agricultural region. Captures of field voles were too few for analysis in the forest region. Among species, captures were not synchronous in the agricultural region but captures of wood mice and bank voles were synchronous in the forest region. These results suggest a role of landscape structure for the population dynamics of these species, rather than differences in predator function.
\end{abstract}

J. Loman (jon.loman@zooekol.lu.se), Dept of Animal Ecology, Lund University, SE-22362 Lund, Sweden.

Several patterns of population dynamics are known for small mammals. Cyclic populations are well known, in particular for boreal microtine species (Elton 1942, Norrdahl 1995, Korpimäki et al. 2004), but also in other landscapes (Lambin et al. 2006). Some species have irregular population peaks that may correlate to years of superabundant food (Hoffmeyer and Hansson 1974, Jensen 1982, Wolff 1996, McShea 2000). Landscape structure is considered one factor affecting the dynamics, directly or indirectly. A patchy landscape, like that in southern Scandinavia, is less associated with cycles than a continuous one, like in northern Scandinavia (Wolff 1980, Lindén 1988). This difference has been explained by the higher number of generalist predators in the heterogeneous and patchy southern landscape (Erlinge et al. 1983, Hanski et al. 1991, Klemola et al. 2002), but the difference in landscape structure may have a more direct influence. For example, heterogeneity has been directly involved as an explanation for low amplitude population fluctuations (Wiens 1976).
Given low amplitude fluctuations in a patchy landscape, this can at the patch level be compatible with two opposing local patterns. Firstly, this landscape pattern can be due to synchronous low amplitude fluctuations in all patches. Secondly, the individual patches may experience high amplitude but if these are asynchronous, the aggregate dynamics of the landscape will be one of low amplitude fluctuations.

Assuming that abundant generalist predators are responsible for the lack of cyclicity, one should expect the first pattern. This assumes that the generalist predators involved typically have home ranges that in some respect are larger than patch grain or move in response to variation in prey density (Norrdahl and Korpimäki 1996). Also, if generalist predators are present and synchronize dynamics in different patches, one should also expect a high degree of between species synchrony among prey populations.

If the second pattern applies, more direct patch structure-related phenomena may be involved in the explanation for low amplitude fluctuations in patchy landscapes. 
If so, synchrony should also be lowest among the most isolated patches (Ranta et al. 1995). These differences among patterns are not clear cut and more specifications may be needed to separate between the alternatives. Still, these considerations motivated the following study where small mammal dynamics are compared among two landscapes only some $30 \mathrm{~km}$ apart in Dalsland, western Sweden. One is in a forest region, dominated by largely continuous mixed evergreen and deciduous forests that are a continuation of the boreal forests of northern Scandinavia. The other is in a flat agricultural region, dominated by cropped fields with small habitat islands. Some larger woods were also present in this area. The climate is similar and the distance between the two areas is short enough to assume cover by the same nomadic predators, if at all important. Thus, any differences in dynamics found should be related to landscape structure, directly or indirectly.

\section{Material and methods}

\section{Study area}

The study was carried out in Dalsland, on the west side of Lake Vänern in central Sweden. Dalsland can be consid- ered a transition zone between the boreal Scandinavian forest area and a more diverse southern habitat with a large fraction of agricultural land (Hansson and Henttonen 1985).

\section{Study sites}

There were four study sites in the forest region $\left(58^{\circ} 00^{\prime} \mathrm{N}\right.$, $12^{\circ} 30^{\prime} \mathrm{E}$ ). All these sites were covered by a mixed forest and also included open areas and forest margins, typical of the area. It is not a typical boreal forest of northern Scandinavia where evergreens dominate and open fields are very sparse. Still, it contrasts markedly to the open agricultural landscape to which it is here compared. The maximum distance between the sites was $4 \mathrm{~km}$. In the agricultural region $\left(57^{\circ} 30^{\prime} \mathrm{N}, 12^{\circ} 30^{\prime} \mathrm{E}\right)$, there were two study sites in the small forest and 19 sites in the small habitat islands. The forest sites in the agricultural area were similar in vegetation to the sites in the forest area. However, the forests were small (approx. $50 \mathrm{ha}$ ) and discontinued by agricultural fields. There was an intra-habitat island difference in vegetation, but they all contrasted to the surrounding cropped field. They varied from being abandoned grazed land with thick grassy vegetation to being completely covered by deciduous trees. The maximum distance between

Table 1. Study sites with information on the year(s) of study. For each species, it is also indicated if it was ever captured at a site. 'Island' habitat may or may not be covered by forest but is always small and set off from fields. 'Forest' habitat is continuous with forests at least 50 ha in size. Agric. = agricultural region.

\begin{tabular}{|c|c|c|c|c|c|c|c|c|}
\hline Region & Habitat & Site & Year(s) & A.s. & C. $g$. & M. agr. & M. musc. & M. min. \\
\hline \multirow[t]{21}{*}{ Agric. } & \multirow[t]{19}{*}{ 'Island' } & 1 & 1985,1986 & + & 0 & 0 & 0 & 0 \\
\hline & & 2 & $1985,1987-1991$ & + & + & + & + & 0 \\
\hline & & 3 & 1985 & + & 0 & 0 & 0 & 0 \\
\hline & & 4 & 1985,1987 & + & 0 & + & 0 & 0 \\
\hline & & 5 & $1985,1986,1988-1991$ & + & 0 & + & + & 0 \\
\hline & & 6 & 1985,1988 & + & + & 0 & 0 & 0 \\
\hline & & 7 & $1985-1991$ & + & + & + & + & 0 \\
\hline & & 8 & $1985-1990$ & + & 0 & + & 0 & 0 \\
\hline & & 9 & $1985,1988-1991$ & + & 0 & + & 0 & 0 \\
\hline & & 10 & $1985-1991$ & + & 0 & + & + & 0 \\
\hline & & 11 & 1986 & + & + & + & 0 & 0 \\
\hline & & 12 & 1986 & + & 0 & + & 0 & 0 \\
\hline & & 13 & 1986, 1987, 1989-1991 & + & 0 & + & 0 & 0 \\
\hline & & 14 & $1986,1989-1991$ & + & 0 & 0 & 0 & 0 \\
\hline & & 15 & $1986-1991$ & + & + & + & + & + \\
\hline & & 16 & $1986-1991$ & + & + & + & 0 & 0 \\
\hline & & 17 & 1986 & + & 0 & + & 0 & 0 \\
\hline & & 18 & 1986 & 0 & 0 & 0 & 0 & 0 \\
\hline & & 19 & 1986-1991 & 0 & 0 & + & + & 0 \\
\hline & \multirow[t]{2}{*}{ 'Forest' } & $\mathrm{F}$ & $1985-1991$ & + & + & + & + & 0 \\
\hline & & $\mathrm{J}$ & 1985-1991 & + & + & + & + & + \\
\hline \multirow[t]{4}{*}{ Forest } & \multirow[t]{4}{*}{ 'Forest' } & $\mathrm{B}$ & 1986-1991 & + & + & + & + & 0 \\
\hline & & $\mathrm{O}$ & 1985-1991 & + & + & + & 0 & + \\
\hline & & $\mathrm{T}$ & 1985-1991 & + & + & 0 & 0 & + \\
\hline & & $\mathrm{V}$ & 1986-1991 & + & + & + & 0 & + \\
\hline
\end{tabular}


these sites was $15 \mathrm{~km}$. Not all islands were used in all years of study (Table 1).

Trapping was conducted in October 1987-1991. In 1985 and 1986 there were two trapping sessions, in September and November and in October and November respectively. The following results are based on the average of the two.

\section{Trap layout and procedure}

In each of the forest sites (the four in the forest region and two sites in the agricultural region) 36 live traps ("Ugglan special") were set on a $6 \times 6$ grid at $10 \mathrm{~m}$ interval. The 19 habitat island sites were covered by a trap grid with $10 \mathrm{~m}$ intervals. This resulted in two up to 26 traps per site. One of the sites actually comprised three small islands, separated by $20 \mathrm{~m}$ field. There were $18+4+4$ traps at this site. Thus, all sites had a trap density of 100 traps $\mathrm{ha}^{-1}$. The traps were set on day 0 and checked on day 1,2, 3 and 4 . Captured animals were weighed, marked and immediately released. Total number of different individuals trapped was used as a measure of density at the sites. Because wood mice are found in fields surrounding the habitat islands (Loman 1991), attempts to calculate actual populations sizes could be misleading. Also, very few captures in some years and sites yielded data that was not suitable for calculations of populations sizes by capture-mark-recapture methods.

\section{Analysis}

To test for possible cyclicity, the catches were correlated to the three- and four-year lagged values. With seven years of data this gave three data points per test for the four year lag tests, and four data points for the three year lag tests. A positive correlation was considered an indication of a 3- or 4 -year cycle, respectively. This was done, within each region, for all sites aggregated and also for each site separately. Only sites studied for at least five (out of seven) years and with at least one capture of the respective species were tested.

The degree of within-species-among-patch-synchrony was assessed by the Kendall coefficient of concordance. To test if localities were more synchronous than expected under a random null hypothesis, the Friedmann test statistics was used. These statistics require identical, unbroken time series for all included localities. Data was available from seven of the localities for all seven years from 1985 to 1991. For nine more localities, data for five or six years were available (in all 13 missing data points). These missing data points were therefore replaced by imputed values according to either of two methods. Least square estimates from the model Locality + Year provide the most accurate prediction from a linear model. However because this model assumes a year effect, it will systematically bias the dataset towards synchrony. Therefore, also a more conservative set of imputed values were used. These were the average of all non-missing values for the respective locality. In addition, for each analysed species, only localities where at least one individual (in any year) was captured were included in the analyses. The full data set of 25 sites was used for the figures and the analysis of species synchrony.

\section{Results}

The most common species was the wood mouse Apodemus sylvaticus. It dominated in the habitat islands but was similar in abundance to the bank vole Clethrionomys glareolus in forest sites, both in the forest area and in the agricultural area (Table 2). The field vole Microtus agrestis was equally common to the bank vole in habitat islands and only occasional in forest sites. The house mouse Mus musculus was occasionally found in the agricultural area. Occasional harvest mice Micromys minutus were also found in this region while it was more common in the forest region.

There were substantial among-year fluctuations in abundance. In the agricultural region, wood mice fluctuated three-fold and in the forest region almost eight-fold (Table 3). For bank voles, the contrast between the two regions was even greater; a maximum two-fold variation in the agricultural region but up to a 15 -fold variation in the forest region. Also the field vole fluctuated in the agricultural region. However, it was too rare for a meaningful statement about the forest region.

There were little indications of cycles; within region dynamics for wood mice and bank voles showed no signi-

Table 2. Number of different animals captured at the different site categories. Also given is a density index (= density), number of different animals captured per trap (n) and trapping period. Agric. = agricultural region.

\begin{tabular}{|c|c|c|c|c|c|c|c|}
\hline Region & Habitat & & Wood mice & Bank voles & Field voles & M. musculus & M. minutus \\
\hline \multirow[t]{2}{*}{ Agric. } & 'island' & $\mathrm{n}$ & 1079 & 32 & 46 & 11 & 2 \\
\hline & & density & 1.89 & 0.05 & 0.07 & 0.02 & 0.00 \\
\hline \multirow[t]{2}{*}{ Agric. } & 'non-island' & $\mathrm{n}$ & 293 & 216 & 15 & 4 & 1 \\
\hline & & density & 0.58 & 0.43 & 0.03 & 0.01 & 0.00 \\
\hline \multirow[t]{2}{*}{ Forest } & 'non-island' & $\mathrm{n}$ & 257 & 198 & 4 & 0 & 48 \\
\hline & & density & 0.27 & 0.21 & 0.00 & 0.00 & 0.05 \\
\hline
\end{tabular}


Table 3. Maximum and minimum number of animals captured per species, region and year. Agric. = agricultural region.

\begin{tabular}{lllll}
\hline & $\begin{array}{l}\text { Agric. } \\
\text { Min. }\end{array}$ & Max. & $\begin{array}{l}\text { Forest } \\
\text { Min. }\end{array}$ & Max. \\
\hline Wood mice & 125 & 359 & 10 & 75 \\
Bank voles & 27 & 47 & 5 & 76 \\
Field voles & 3 & 19 & 0 & 2 \\
\hline
\end{tabular}

ficant positive correlations with 3- or 4-year lagged populations sizes (Table 4). This was true both for the average site and for the aggregated site data for these species. For the field voles, where scant data meant that only aggregated site data could meaningfully be tested, there was indeed a suggestion of a positive correlation between populations size and 3- or 4-year lagged data.

Using only full seven years suites, no significant site synchrony could be detected (Table 5). However, with only four or less sites per region, the power of these tests were poor. Increasing the number of sites by including imputed values, it was found that fluctuations in wood mouse catch were synchronous in both regions (Fig. 1). In particular it should be noted that this was true when using the conservative imputed values (site means). The degree of synchrony was higher in the forest region than in the agricultural region. For the bank vole, no significant synchrony could be detected but there was some indication of synchrony in the forest region. Field voles in the agricultural region fluctuated in synchrony while captures in the northern region were too few for a meaningful test. This was also true for the house mouse and for harvest mice.

In the agricultural region, there was no suggestion of synchronous fluctuations among the three common ro- dent species (Fig. 2, Table 6). In the forest region, captures of wood mice and bank voles were correlated. The pattern of field vole dynamics in the forest regions was in synchrony with that of the other two species, but captures were few and the correlations non-significant.

\section{Discussion}

Three- to four-year cycles in the dynamics of voles, including bank voles and field voles, are well known from northern Scandinavia (Hörnfeldt 1994). Wood mice are usually not considered cyclic (Christiansen 1983), and are not found in northern Scandinavia. In fact, the northern limit of their distribution is only some $100 \mathrm{~km}$ north of the study area. Because the present study is based on seven years of data only, it is not well suited to conclusively confirm or reject the presence of cycles. However, the information that is available gives little suggestion of cycles for any of the study species. This may reflect the general weakening of Scandinavian rodent cycles that has been noticed in recent years (Strann et al. 2002). In addition, the study area is situated at the southern limit of where cycles previously have been described in Scandinavia (Hanski et al. 1991).

The negative correlation found in the cyclicity tests could in principle suggest longer, 6-8-year cycles. However, this have never been reported here. Besides, with six similar tests, an argument can be made to only consider a p-level of $0.05 / 6=0.008$ as significant. This would only leave bank voles in the agricultural region $(p=0.003$, Table 4). I prefer to disregard also this and see the tests as being one-tailed.

Large scale cyclicity implies synchrony among sites. However, also in the absence of cyclicity, synchrony is pos-

Table 4. Tests for cyclicity hypotheses. r-values in the 'Combined' columns are correlations based on total catch per species, region and year. The actual catch values for each species, region and year are the sum of standardised values for the component sites. Standardised means that the values for each site are scaled (within species) to the interval 0 to 1 , where 0 and 1 represent the year with the lowest and highest catch for the site. Thus the combined data are not biased towards sites with large total catch. p-values for the correlation coefficients are meaningless due to the low power of the test (few DF) and not given. $r$-values in the 'Average' columns are the average $\mathrm{r}$-value for corresponding correlations within sites in a region. The significance is tested by a one-sample t-test for the difference of this average from zero. DF is thus the number of sites minus 1 . Because few field voles were captured, only the combined data for the agricultural region yielded sufficient data for meaningful tests for this species. Agric. = agricultural region .

\begin{tabular}{|c|c|c|c|c|c|c|c|c|c|c|}
\hline & & \multicolumn{4}{|c|}{ Wood mice } & \multicolumn{4}{|c|}{ Bank voles } & \multirow{2}{*}{$\begin{array}{l}\text { Field voles } \\
\text { Agric. }\end{array}$} \\
\hline & & Agric. & & Forest & & Agric. & & Forest & & \\
\hline \multicolumn{2}{|c|}{ Lag: } & Combined & Average & Combined & Average & Combined & Average & Combined & Average & Combined \\
\hline \multirow[t]{4}{*}{3} & $\mathrm{r}$ & -0.85 & $-0.37^{\circ}$ & 0.04 & $0.07^{\circ}$ & -0.46 & 0.21 & -0.04 & 0.21 & 0.89 \\
\hline & $\mathrm{t}$ & & 2.45 & & 0.36 & & 1.03 & & 0.61 & \\
\hline & DF & 4 & 11 & 4 & 3 & 4 & 5 & 4 & 3 & 4 \\
\hline & $\mathrm{p}$ & & 0.033 & & 0.72 & & 0.35 & & 0.59 & \\
\hline \multirow[t]{4}{*}{4} & $\mathrm{r}$ & 0.08 & 0.02 & -0.72 & -0.61 & -0.37 & -0.54 & -1.0 & -0.16 & 0.99 \\
\hline & $\mathrm{t}$ & & 0.13 & & 3.02 & & 5.43 & & 0.46 & \\
\hline & DF & 3 & 11 & 3 & 3 & 3 & 5 & 3 & 3 & 3 \\
\hline & $\mathrm{p}$ & & 0.90 & & 0.057 & & 0.003 & & 0.68 & \\
\hline
\end{tabular}


Table 5. Site synchrony test. 'No missing' only includes sites trapped during all seven years of study. 'Imputed, LS' includes all sites trapped for at least six years, missing data were replaced by least squares estimates. 'Imputed, mean' also includes all sites trapped for at least six years. However, missing data are replaced by site means. For each set of sites, n (number of included sites), Kendall's coefficient of concordance (= Kend. c. c.), Friedmann's test statistics (= Fried. t. s.) and p (for a significant synchrony) is given. Agric. = agricultural region.

\begin{tabular}{|c|c|c|c|c|c|c|c|}
\hline & & $\begin{array}{l}\text { Wood mice } \\
\text { Agric. }\end{array}$ & Forest & $\begin{array}{l}\text { Bank voles } \\
\text { Agric. }\end{array}$ & Forest & $\begin{array}{l}\text { Field voles } \\
\text { Agric. }\end{array}$ & Forest \\
\hline \multirow[t]{4}{*}{ No missing } & $\mathrm{n}$ & 4 & 2 & 3 & 2 & 4 & 1 \\
\hline & Kend. c. c. & 0.51 & 0.70 & 0.39 & 0.76 & 0.38 & \\
\hline & Fried. t. s. & 12.2 & 8.36 & 6.93 & 9.16 & 9.20 & \\
\hline & $\mathrm{p}$ & 0.057 & 0.21 & 0.33 & 0.17 & 0.16 & \\
\hline \multirow[t]{4}{*}{ Imputed, LS } & $\mathrm{n}$ & 11 & 4 & 6 & 4 & 11 & 3 \\
\hline & Kend. c. c. & 0.30 & 0.71 & 0.26 & 0.42 & 0.31 & 0.25 \\
\hline & Fried. t. s. & 19.8 & 17.0 & 9.21 & 10.2 & 20.2 & 4.43 \\
\hline & $\mathrm{p}$ & 0.003 & 0.009 & 0.16 & 0.12 & 0.003 & 0.62 \\
\hline \multirow[t]{4}{*}{ Imputed, mean } & $\mathrm{n}$ & 11 & 4 & 6 & 4 & 11 & 3 \\
\hline & Kend. c. c. & 0.28 & 0.71 & 0.19 & 0.47 & 0.20 & 0.21 \\
\hline & Fried. t. s. & 18.4 & 17.0 & 6.93 & 11.3 & 12.9 & 3.86 \\
\hline & $\mathrm{p}$ & 0.005 & 0.009 & 0.33 & 0.080 & 0.045 & 0.70 \\
\hline
\end{tabular}

sible and a search for this trait in the dynamics is of interest (Lundberg et al. 2000). In the present study, wood mice dynamics was clearly synchronous among sites. The fact that synchrony was as high, or possibly higher in the agricultural region, suggests that landscape structure as such is not sufficient to dampen regional population fluctuations (and thus also possible cycles) on a regional scale. Some questions remain with respect to the bank voles; for this species, there were hints that synchrony might be somewhat stronger in the forest region. Also in this case would regard to multiple tests mean a reduction of the p-value limit to $0.05 / 6=0.008$. This would leave the wood mouse in agricultural habitat significant and wood mouse in forest habitat almost significant.

Within-region synchrony, on a scale corresponding to that of this study, has previously been shown in several instances: Rattus rattus in forest plots in India (Shanker and Sukumar 1999), Microtus arvalis in Poland (Mackin-Rogalska and Nabagl 1990), Clethrionomys glareolus and Microtus agrestis in Finland (Huitu et al. 2003), Apodemus sylvaticus and Clethrionomys glareolus in England (Flowerdew et al. 2004), Clethrionomys glareolus in Norway (Steen et al.

Table 6. Test of synchrony in site dynamics, within regions, between species. Agric. = agricultural region.

\begin{tabular}{lllll}
\hline Region & & $\mathrm{n}$ & $\mathrm{r}$ & $\mathrm{p}$ \\
\hline Agric. & wood mice-bank voles & 7 & -0.60 & 0.16 \\
& wood mice-field voles & 7 & -0.24 & 0.60 \\
& bank voles-field voles & 7 & 0.14 & 0.76 \\
Forest & wood mice-bank voles & 7 & 0.81 & 0.027 \\
& wood mice-field voles & 7 & 0.59 & 0.17 \\
& bank voles-field voles & 7 & 0.56 & 0.19 \\
\hline
\end{tabular}

1996). The latter study also found that more distant sites (more than $100 \mathrm{~km}$ ) were not synchronous.

What is the mechanism behind the observed synchrony? Three different mechanisms may be responsible. Extreme weather situation with catastrophic mortality could in principle synchronize population lows (Kaitala and Ranta 2001) over large areas. Such conditions are probably rare but heavy winter rain followed by frost in open mountain areas could provide an example. Models and field experiments have supported the possibility of the intuitively attractive hypothesis that populations are synchronized by means of predation from nomadic predators, in particular raptors (Ims and Steen 1990, Norrdahl and Korpimäki 1996). Finally, frequent migrations between neighbouring populations could level out local population variation and provide synchronization. If this is important, one would expect local populations to be more synchronous in a homogeneous than in a patchy landscape. In contrast, this landscape factor should be less important if nomadic predators are the main synchronizing agent.

Huitu et al. (2003) indeed found a higher degree of intra-specific population synchrony for both species in the more continuous of two landscape types studied. This was for bank voles the forest landscape and for field voles a more open landscape. This corresponds to the findings for bank voles in the present study. It is not entirely clear what the more continuous landscape is for wood mice. However, this species is frequently found in the matrix of the agricultural landscape, cropped fields (Loman 1991), so the fact that sites in both regions were synchronous for this species supports feasibility of the last of the three mechanisms mentioned above. This gives landscape structure a role in the dynamics. This does, of course, not deny the possibility that predation also contributes to synchronization. However, also in northern England asynchronous 

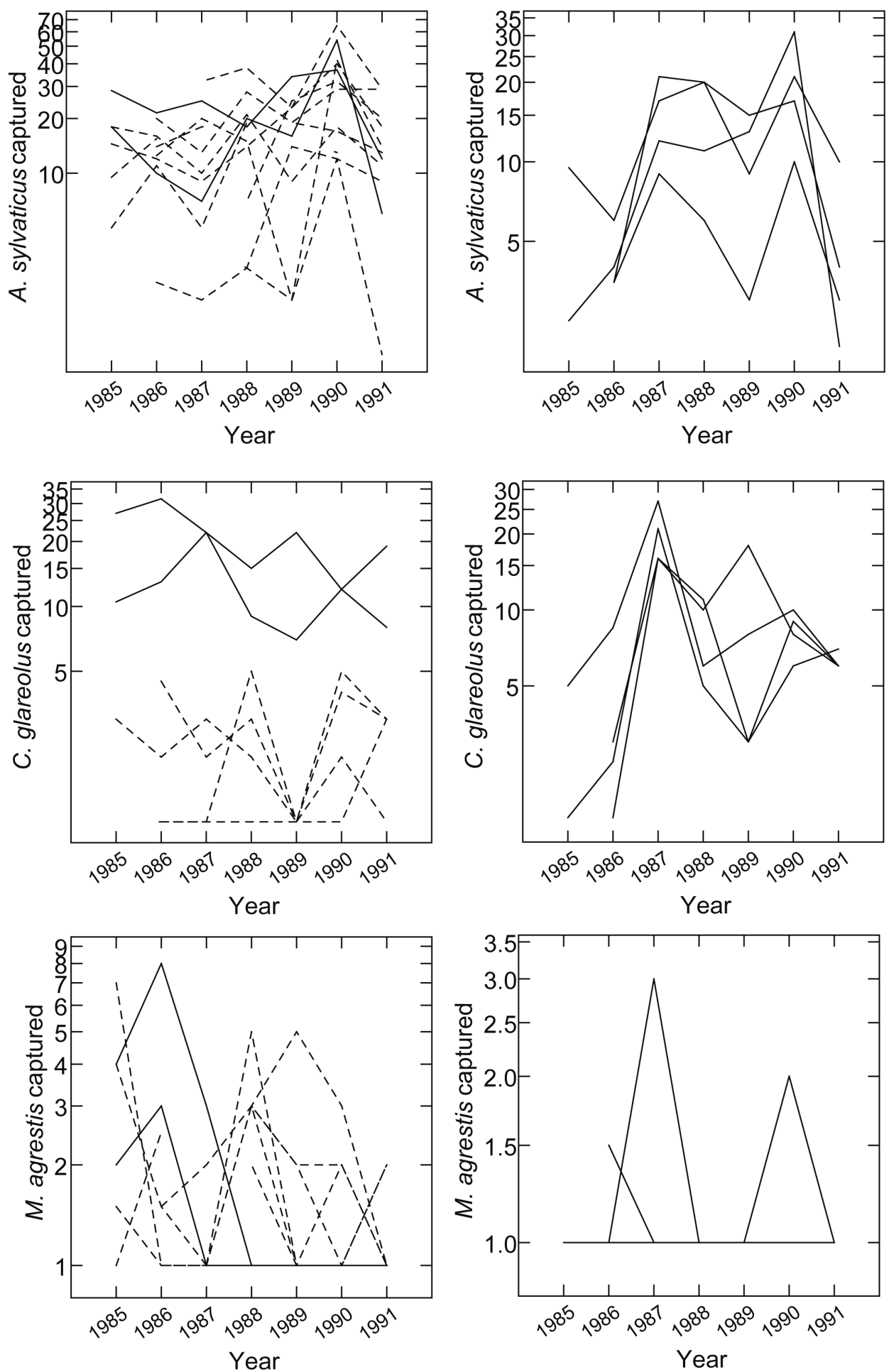

Figure 1. Among-site synchrony. In the agricultural region, the two forest sites are indicated with continuous lines while the habitat islands are dashed. Missing years are not estimated, i.e. the line segment before and after a missing year is not drawn. 


\section{Forest region}

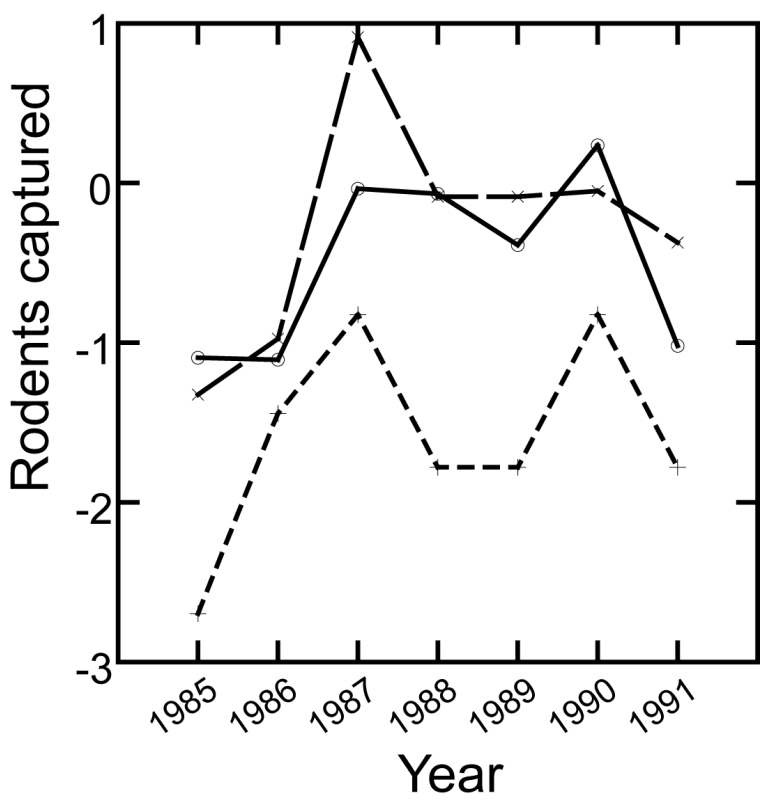

Agric. region

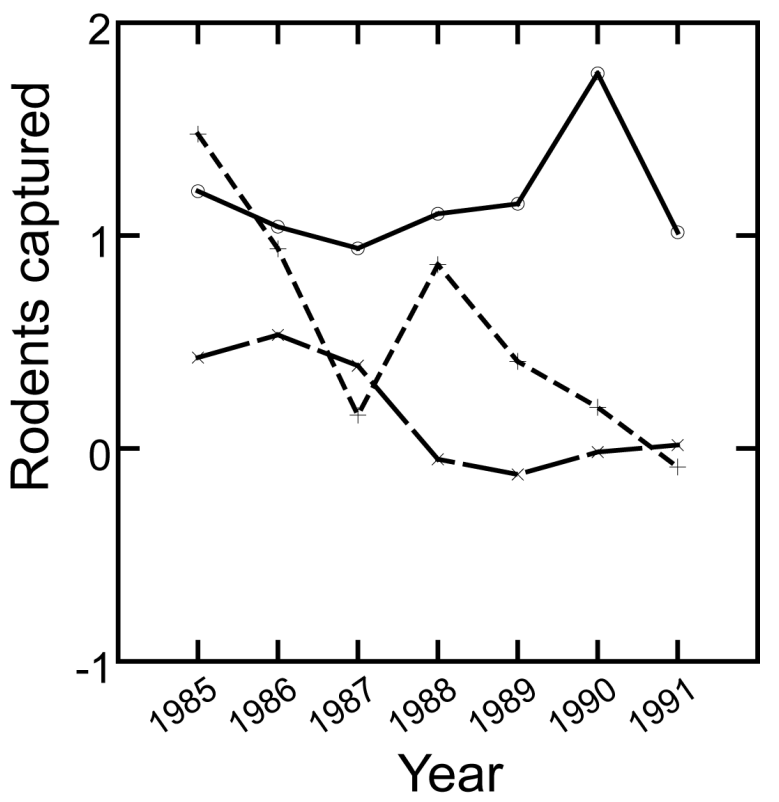

dynamics of voles (Microtus agrestis) has been found (Brandt and Lambin 2007), despite the fact that weasels roamed at a larger scale and potentially could synchronize the local populations. The lack of synchrony for bank vole populations in the agricultural area may thus, under this interpretation, be due to a lack of connectivity among patches for this species. This in turn may be a factor behind the low degree of cyclicity observed for this species in southern Scandinavia, where this type of landscapes is more common than in northern areas.

In areas with vole cycles, populations usually fluctuate in inter-specific synchrony (Huitu et al. 2004). Also in areas with non-cyclic rodent populations inter-specific synchrony may be present. This can be caused by masting tree species (McCracken et al. 1999, McShea 2000). In contrast, Jensen (1982) found little synchrony between the fluctuations of yellow-neck mice Apodemus flavicollis and bank vole numbers in a beech forest. A mixed picture is presented by Litvinov et al. (2007) for several Apodemus and Clethrionomys species in the Altai mountains. Wendland (1981) found Microtus arvalis, M. agrestis and Apodemus flavicollis to fluctuate asynchronously. In the present case, the two common species fluctuated in synchrony in one area but not in the other. In the forest region, where fluctuations were synchronous, the landscape structure was similar for both species, but in the agricultural regions, the landscape was more patchy for bank voles than for wood mice, as the latter species utilizes not only the habitat islands but also the matrix, cropped fields. This supports the hypothesis that landscape structure, rather than predation, affects the pattern of fluctuation. However, this effect may be indirect; the dynamics of wood mice is largely affected by different resources than that of bank voles, waste grain and other resources in the fields. By area, this is the dominating habitat and dynamics here may spill over to the habitat islands where densities were assessed. Both these hypotheses somewhat reduce the role of predators for population cycle synchronization. The lack of inter-specific synchrony in the agricultural region also directly suggests that generalist predation is not the only important factor governing the dynamics of these species. If so, one would expect intra-specific synchrony.

Acknowledgements - This study has been supported by grants from the Swedish National Environmental Protection Board and the Swedish Council for Forestry and Agricultural Research. Lennart Hansson has kindly commented on the manuscript.

\section{References}

Brandt, M. J. and Lambin, X. 2007. Movement patterns of a specialist predator, the weasel Mustela nivalis exploiting asynchronous cyclic field vole Microtus agrestis populations. Acta Theriol. 52: 13-25.

Christiansen, E. 1983. Fluctuations in some small rodent populations in Norway 1971-1979. - Holarct. Ecol. 6: 24-31.

Figure 2. Between-species synchrony. 
Elton, C. 1942. Voles, mice and lemmings: problems in population dynamics - Oxford Univ. Press.

Erlinge, S. et al. 1983. Predation as a regulating factor on small rodent populations in southern Sweden. - Oikos 40: 3652.

Flowerdew, R. J. et al. 2004. Live trapping to monitor small mammals in Britain. - Mammal. Rev. 34: 31-50.

Hanski, I. et al. 1991. Specialist predators, generalist predators, and the microtine rodent cycle. - J. Anim. Ecol. 60: 353367.

Hansson, L. and Henttonen, H. 1985. Gradients in density variations of small rodents: the importance of latitude and cover. - Oecologia 67: 394-402.

Hoffmeyer, I. and Hansson, L. 1974. Variability in number and distribution of Apodemus flavicollis (Melch.) and A. sylvaticus (L.) in south Sweden. - Z. Säugetierkunde 39: 15-23.

Huitu, O. et al. 2003. Landscape effects on temporal and spatial properties of vole population fluctuations. - Oecologia 135: 209-220.

Huitu, O. et al. 2004. Competition, predation and interspecific synchrony in cyclic small mammal communities. - Ecography 27: 197-206.

Hörnfeldt, B. 1994. Delayed density dependence as a determinant of vole cycles. - Ecology 75: 791-806.

Ims, R. A. and Steen, H. 1990. Geographical synchrony in microtine population cycles: a theoretical evaluation of the role of avian predators. - Oikos 57: 381-387.

Jensen, T. S. 1982. Seed production and outbreaks of non-cyclic rodent populations in deciduous forests. - Oecologia 54: 184-192.

Kaitala, V. and Ranta, E. 2001. Is the impact of environmental noise visible in the dynamics of age-structured populations? - Proc. R. Soc. Lond. B 268: 1769-1774.

Klemola, T. et al. 2002. Specialist and generalist natural enemies as an explanation for geographical gradients in population cycles of northern herbivores. - Oikos 99: 83-94.

Korpimäki, E. et al. 2004. The puzzles of population cycles and outbreaks of small mammals solved. - BioScience 54: 10711079.

Lambin, X. et al. 2006. Vole population cycles in northern and southern Europe: is there a need for different explanations for single pattern? - J. Anim. Ecol. 75: 340-349.

Lindén, H. 1988. Latitudinal gradients in predator-prey interactions, cyclicity and synchronism in voles and small game populations in Finland. - Oikos 52: 341-349.
Litvinov, Y. N. et al. 2007. Structural-temporal organization of a rodent community in the Teltskaya taiga, Altai mountains. Russ. J. Ecol. 38: 413-418.

Loman, J. 1991. The small mammal fauna in an agricultural landscape in southern Sweden with special reference to the wood mouse Apodemus sylvaticus. - Mammalia 55: 91-96.

Lundberg, P. et al. 2000. Population variability in space and time. - Trends Ecol. Evol. 15: 460-464.

Mackin-Rogalska, R. and Nabaglo, L. 1990. Geographical variation in cyclic periodicity and synchrony in the common vole, Microtus arvalis. - Oikos 59: 343-348.

McCracken, K. E. et al. 1999. Relationships between seed fall of three tree species and Peromyscus leucopus and Clethrionomys gapperi during 10 years in an oak-pine forest. - J. Mammal. 80: $1288-1296$.

McShea, W. J. 2000. The influence of acorn crops on annual variation in rodent and bird populations. - Ecology 81: 228238.

Norrdahl, K. 1995. Populations cycles in northern small mammals. - Biol. Rev. 70: 621-637.

Norrdahl, K. and Korpimäki, E. 1996. Do nomadic avian predators synchronize population fluctuations of small mammals? a field experiment. - Oecologia 107: 478-483.

Ranta, E. et al. 1995. Synchronity in population dynamics. Proc. R. Soc. Lond. B 262: 113-118.

Shanker, K. and Sukumar, R. 1999. Synchrony in small mammal populations of montane forest patches in southern India. $-\mathrm{J}$. Anim. Ecol. 68: 50-59.

Steen, H. et al. 1996. Spatial and temporal patterns of small-rodent population dynamics at a regional scale. - Ecology 77 : 2365-2372.

Strann, K.-B. et al. 2002. Is the heart of the Fennoscandian rodent cycle still beating? A 14-year study of small mammals and Tengmalm's owl in northern Norway. - Ecography 25: 81-87.

Wendland, V. 1981. Cyclic population changes in three mouse species in the same woodland. - Oecologia 48: 7-12.

Wiens, J. A. 1976. Populations responses to patchy environments. - Annu. Rev. Ecol. Syst. 7: 81-120.

Wolff, J. O. 1980. The role of habitat patchiness in the population dynamics of snowshoe hares. - Ecol. Monogr. 50: 111130.

Wolff, J. O. 1996. Population fluctuations of mast-eating rodents are correlated with production of acorns. - J. Mammal. 77: 850-856. 